\title{
AN AUTOMATED RAILWAY STATION TRAFFIC CONTROL SYSTEM
}

\author{
J. A. Enokela ${ }^{1, *}$ and K. L. Oladejo ${ }^{2}$ \\ 1,2 Dept. of Electrical and EleCtronics EnGr. Fed. University of Agriculture, MaKURdi, BenUe State, NiGERIA \\ E-mail addresses: ${ }^{1}$ jonajapeno@gmail.com;2oladejokayode@gmail.com
}

\begin{abstract}
Majority of accidents experienced with railway transportation involve collision with automobiles or other vehicles and collision with other trains. These collisions can be averted by putting safety measures in place. Part of the measures can be achieved by using computerized railway station traffic control systems that use microcontrollers and electromechanical devices to shift traffic from one rail lane to another and also to operate the level crossing gate. The two major stages of the system being described here are thus the track switching stage and the level crossing gate stage. The system makes use of microcontrollers for decision making. The microcontrollers are programmed to detect signals from sensors and to output the processed signals to control electromagnetic devices through motor drivers. The codes for the microcontrollers were written in PIC Basic programming language and were debugged and compiled using Micro Code Studio Integrated Development Environment. The resultant Hex files were programmed into the memory of the microcontrollers with the aid of a universal programmer. Software simulation was carried out using the Proteus virtual system modeling software. A scaled down prototype of the system was built and tested. The prototype was able to execute all the decisions required to control the given railway station. A practical real life system would require the scaling up of the power required to drive the various motors; the logic of the system would however remain unchanged. The inclusion of the automated traffic control lighting system at the level crossing gate in the system eliminates the fatigue and tedium associated with a manually controlled traffic system. The computerized railway station traffic control system which helps in track switching and level crossing gate traffic control is capable of improving reliability, speed, operational safety and efficiency of the railway transportation system.
\end{abstract}

Keywords: Rail Track Switching, Microcontroller, Rail Level Crossing Gate, Traffic Control

\section{INTRODUCTION}

The railway transportation system provides services to millions of passengers worldwide and is also responsible for the haulage of tones of goods daily. It is a high capacity system and it is economical. The necessity to keep train journeys safe and reliable cannot be overemphasized. A number of recent train accidents especially train-train collisions on the tracks, and trainvehicle collisions at the level crossings, have been attributed to the old methods of signaling and operations [1].The introduction of computerized railway traffic control systems that have automatic safety features will improve the reliability, efficiency, and safety of the railway system both in the station and at the level crossing.

Many attempts have been made to design such systems that will provide a reliable safety measure to the railway. The works discussed in [2] and [3] considered the safety of the rail but they do not extend to safety at the level crossing gate in terms of automatic operation of the gate.
A system that provides efficient rail safety is discussed in [4]. The main shortcoming of this system is that it does not extend its scope to track switching; thus it does not give complete safety as required. The development of a rail safety system explained in [1] shows that automatic track switching can be performed both automatically and manually and also can be controlled by the software from the main control room which gives the system more flexibility of operation. The main drawback of this work is that it does not include the level crossing gate. In the work done discussed in [5] the track switching and level crossing were put into consideration to provide complete rail safety. This work does not extend to the safety within the train parking yard. An elaborate system that uses onboard computer that compares the train's location and speed with authorized speed limits, automatically applying the train's brakes when necessary, is provided by Signalling Solutions [6]. Some applications of the Global Navigation Satellite System (GNSS) to rail traffic are discussed in [7] and [8]. 
In this work, our designed system considered a multitrack railway station; the process of arrival and departure of trains to and from the station was programmed into the memory of a microcontroller and this program handles all traffic related matters within the railway station. Another microcontroller was programmed to handle traffic flow across the two level crossings that are associated with the railway station under study. The microcontrollers take inputs from sensors and, after processing these signals, control motors through relays and drivers to switch tracks and also to operate level crossing gates. Some advantages of our system include:

(i) The design and construction of a computerized railway station traffic control system will ease operation of a point or switch in the event that a train wants to be shunted out of a lane.

(ii) It will assist in sequential parking of train and also notify the operators when the tracks are full.

(iii) It will help in the control of level crossing gates which will reduce, if not totally eliminate, trainvehicle collision.

(iv) The system will help with easy shutting down of lane(s) that require maintenance.

(v) It will assist in prevention of fatal accidents that may be caused by train-train collision.

(vi) The system will reduce, if not eliminate, the fatigue of railway staff at the level crossing junction to control motorists and pedestrians in order to give the train priority to pass at the level crossing junction.

\section{MATERIALS AND METHOD}

\subsection{Architecture of the System}

The proposed railway station traffic control system is made up of two stages: the track switching stage and the level crossing stage. The block diagrams of the system are shown in figure 1 . The block diagrams show that the system is made up of three principal units. The detector unit consists of sensors. Signalling Solutions senses the passage of train with the aid of a specialized sensor known as Eurobalise that is installed in the tracks [6]. Various types of sensors including infrared, strain gauge, and laser may be used [9]. The signal processing unit is the microcontroller itself. This unit takes inputs from the sensors in the detector unit and sends output signals to the control unit that consists of the motor drivers, the motors, visual display units and the alarm system.

The track switching stage depicted in the circuit diagram in figure 2 helps to prevent collision of two trains coming in opposite directions by giving one of the trains the opportunity to follow one track and the other train to follow a different track. It also helps in parking trains in an orderly manner on the parking tracks. Consider the passing and track switching operation for a lane as shown in figure 3 where the sensors are depicted by switches. As the train intercepts the passing sensor SW1 the corresponding LED is turned on to show that the train is passing along the lane. If the train is to be parked along the lane the parking sensor, depicted as SW2, is intercepted and a signal is sent to the microcontroller which operates the track switching arrangement that then enables the train to be parked.
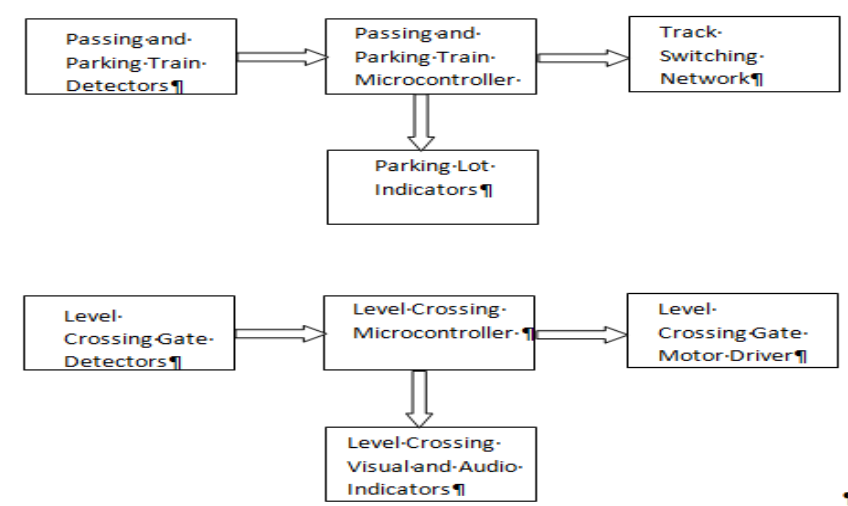

Figure 1: Block Diagrams of Railway Station Traffic Control System

The circuit diagram of the level crossing stage is shown in figure 4 where sensors, represented by switches, are used as inputs to the microcontroller whose outputs control traffic lights for regulating pedestrian and vehicular traffic across the level crossing. The opening and closing of the gates at the level crossing are also controlled by the microcontroller through motors that are driven through $\mathrm{H}$ bridges. The system described here has been designed for Makurdi railway station located in Benue State, Nigeria. The layout of tracks within this station is shown in figure 5 . The software and signaling system may be modified to suit the peculiarities of any other railway station.

\subsection{Software Design}

The software was designed with the aid of flow charts which were translated into codes for the microcontrollers using the Micro Code Studio Integrated Development Environment [10]. The flowchart for the microcontroller that controls the passing and parking of trains is given in figure 6.As shown in figure 5 the three lanes that a passing train can occupy in transit are lane 1 , lane 2 , and lane 3 . The program starts by checking which of these lanes is free for a train to pass through. The appropriate track connecting links are switched into place after the correct decision has been taken. The program ensures that a train is directed to occupy a lane only if the lane is free. 



Figure 2: Circuit Diagram of the Track Switching Stage of Railway Station Traffic Control System

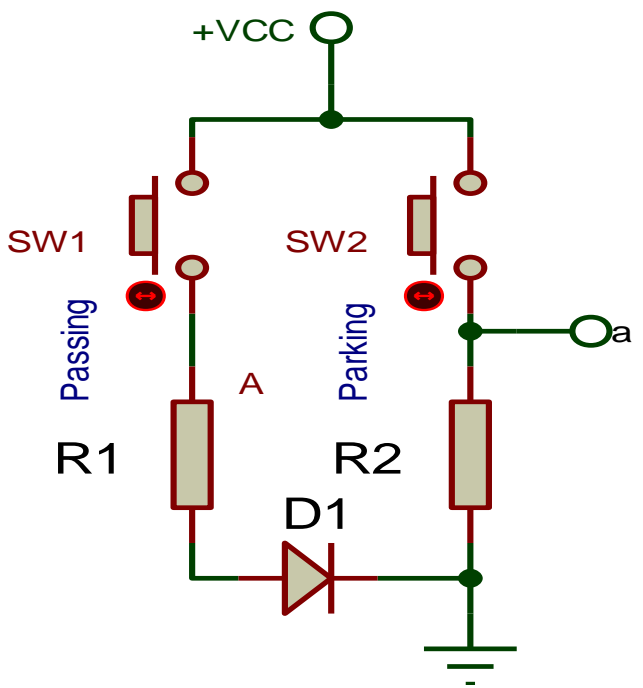

Figure 3: Detector Circuit of Track Switching Stage of Railway Station Traffic Control System

If all the transit lanes are occupied, or if the train is to be parked for a long period for some maintenance action, the train is directed to occupy one of the parking lanes P1, P2, P3, P4, or P5. The sensor corresponding to the parking lane (these sensors are shown in figure 2 as SW13 -SW17) is activated and the appropriate parking light is turned on. An alarm is turned on if all the transit and parking lanes are occupied; the incoming train is then kept waiting before the level crossing
Figure 7 gives the flowchart for the microcontroller that controls the level crossing gate. Four sensors, labeled LA, LB, LC, and LD in figure 4, are used to monitor the arrival and departure of trains and to control the operation of the level crossing gate. Sensors LA and LD are mounted at the far ends of the entry rail to the station, before the level crossing, one at each end. Sensors LB and LC are mounted at the inside of the station before the level crossing, also one at each end. As the train arrives in the station, it triggers sensor LA or LD; a yellow light and an audible alarm are turned on at the level crossing to warn the pedestrians and vehicle drivers of the approach of the train. After the elapse of a preset time interval the light at the level crossing changes to red, the alarm is still turned on, and the level crossing gate closes to pedestrian and vehicular traffic. As the train enters the station and triggers sensor LB, the light at the level crossing turns yellow, the alarm turns off, and after the elapse of a preset time interval, the light turns green and the level crossing gate opens to pedestrian and vehicular traffic. The same sequence of events occurs if the train approaches the station from the other level crossing. In this case, however, sensor LD plays the same role as sensor LA while the role of sensor LC is the same as that of sensor LB. 
If a train is leaving the station instead of arriving it, the roles of the pair of sensors LA, LB or LC, LD are reversed but the sequence of events, however, remains the same. The question of determining whether a train is arriving or leaving a station is resolved by finding out if sensors LA and LD are triggered before sensors LB and LC respectively or vice versa.

The programs for the microcontrollers were written in PIC basic language. The programs were compiled and debugged in the MicroCode Studio Integrated Development Environment. The simulation of the firmware and hardware was carried out using the Proteus Virtual System Modeling (VSM) environment version 8 [11]. The resultant hex file was burnt into the program memory of the microcontroller with the aid of a TOP2007 universal programmer [12].
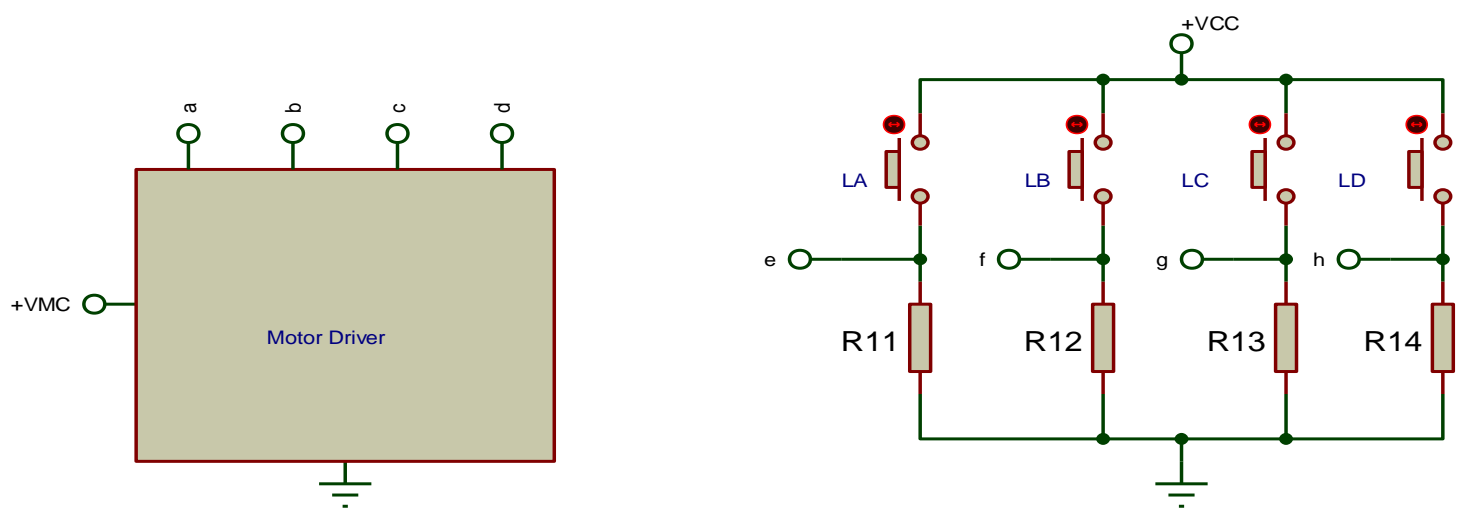

Arrival and Departure Sensors



$\mathrm{R7}$


Level Crossing Lights

Figure 4: Circuit Diagram of the Level Crossing Stage of Railway Station Traffic Control System 


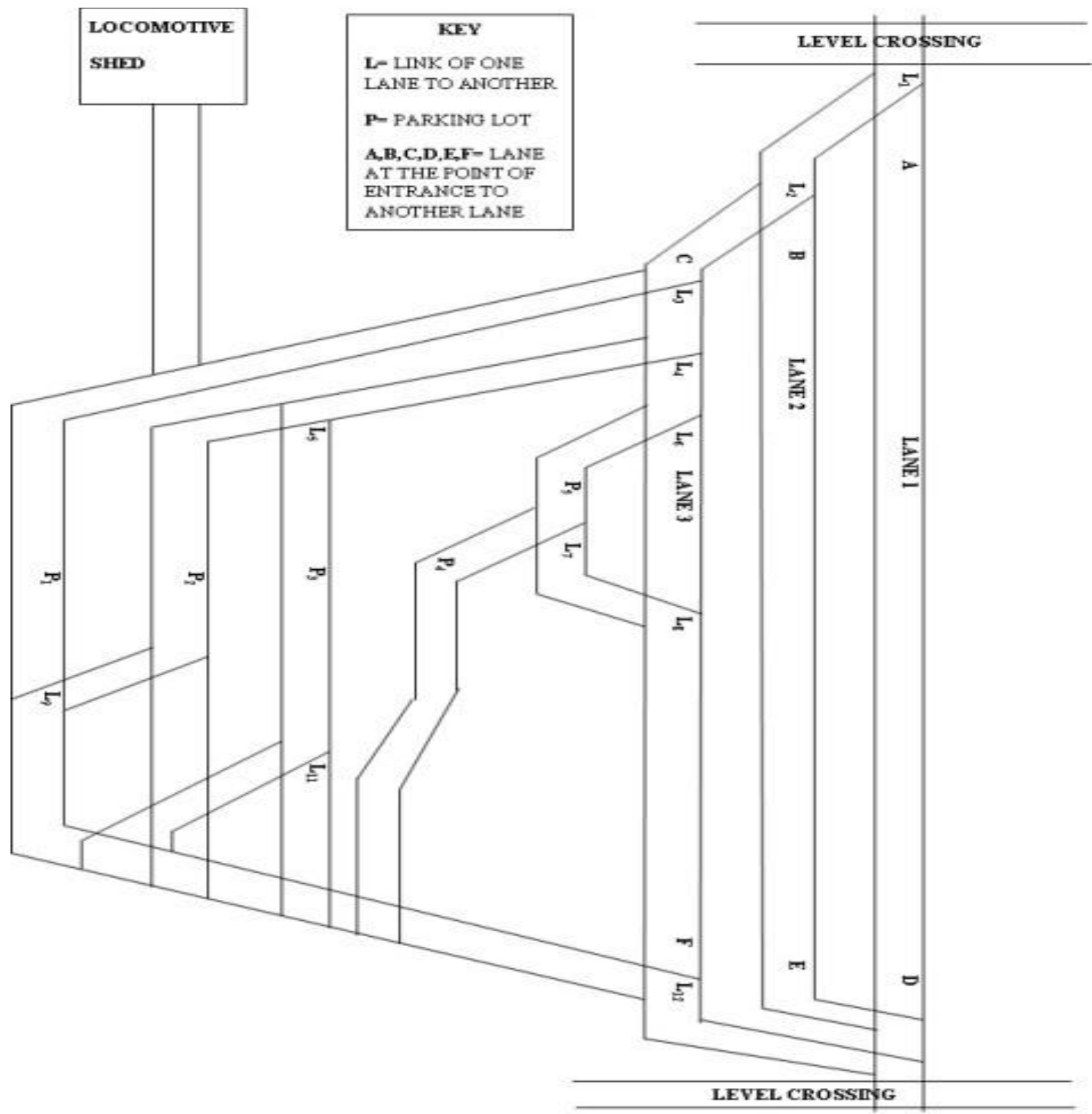

Figure 5: Railway Crossing and Station Yard in Makurdi, Benue State, Nigeria

\section{RESULTS}

Typical screenshots taken during program development are shown in figure 8 and figure 9. The circuits of the track switching stage and level crossing stage were built on vero boards as shown in figures 10 and 11 respectively. Figure 12 shows the prototype of the constructed computerized railway traffic control system. Small model toy trains were run over the tracks shown. Track changes and signaling at the gates were observed to correspond to the desired logic of the design. 


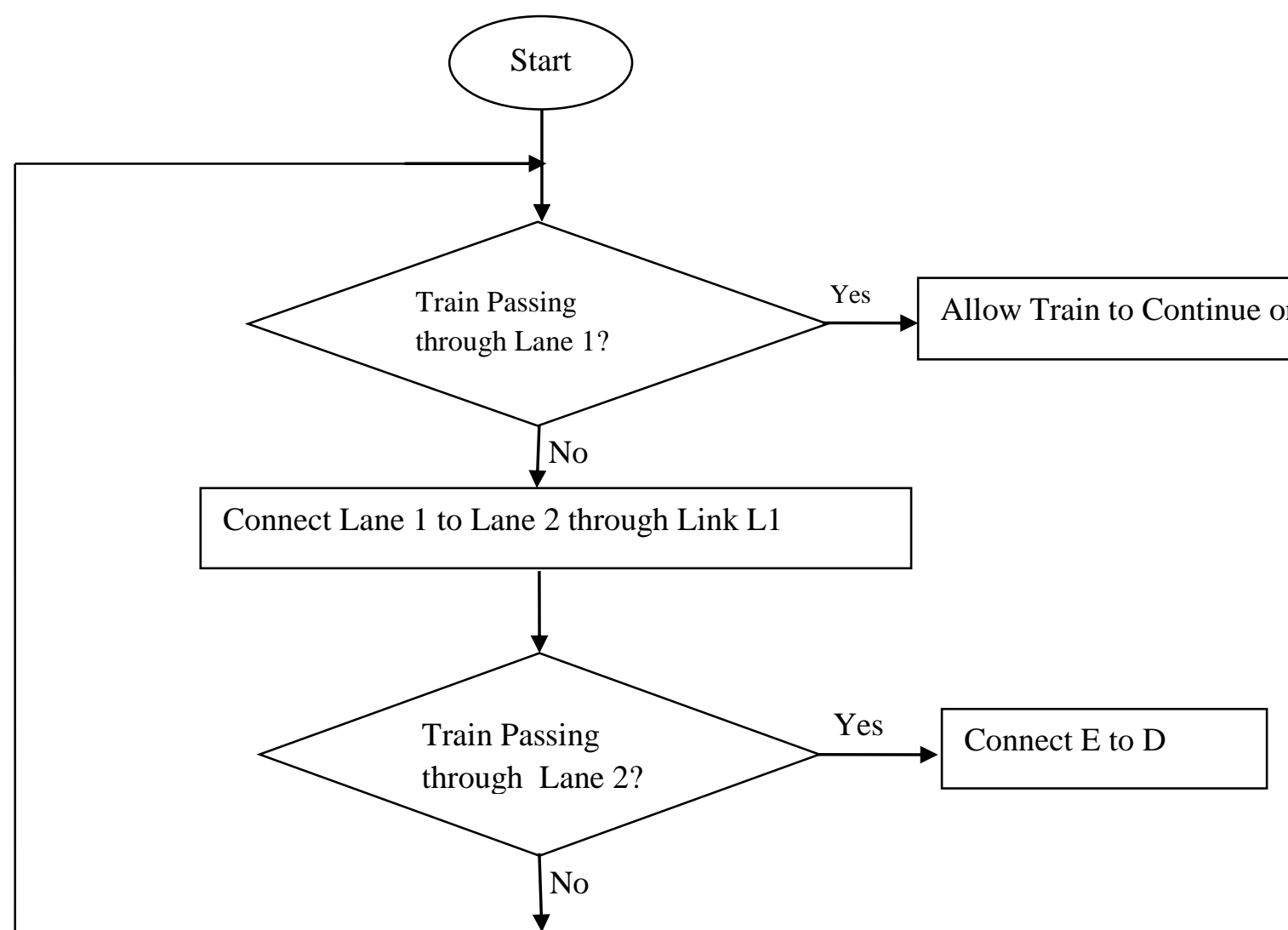

Connect Lane 2 to Lane 3 through Link L2

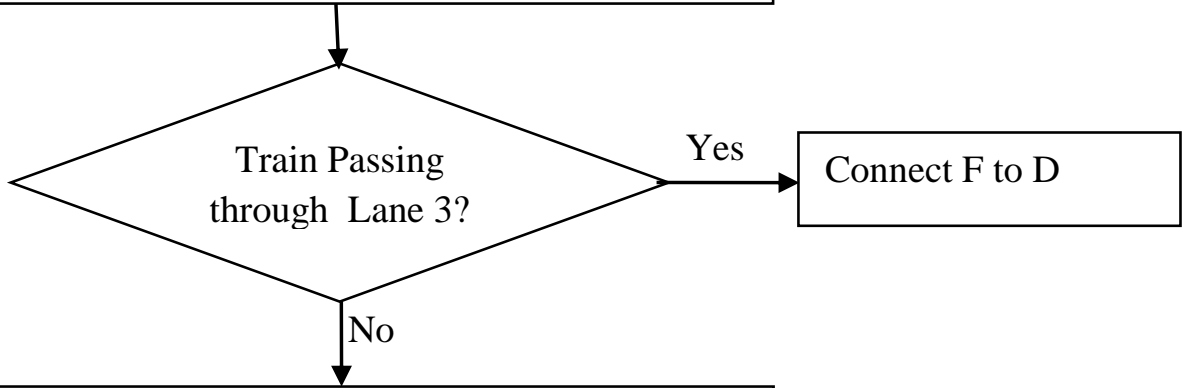

Train must be parking; Search for Free Parking Track



Park Train; Turn On Corresponding Parking Light 




Figure 7: Flowchart for the Level Crossing Gate 


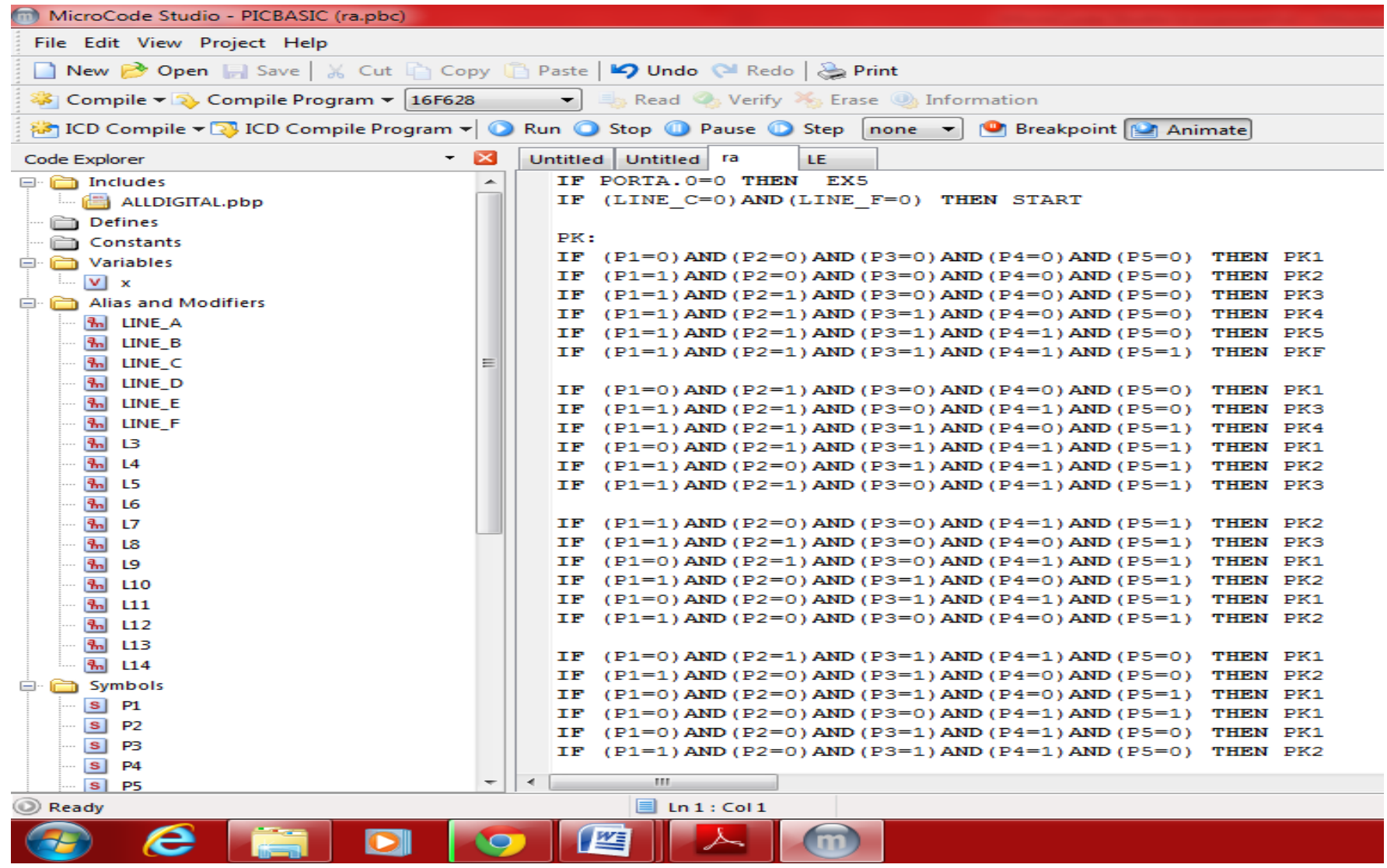

Figure8:A Typical Screenshot during Track Switching Program Development

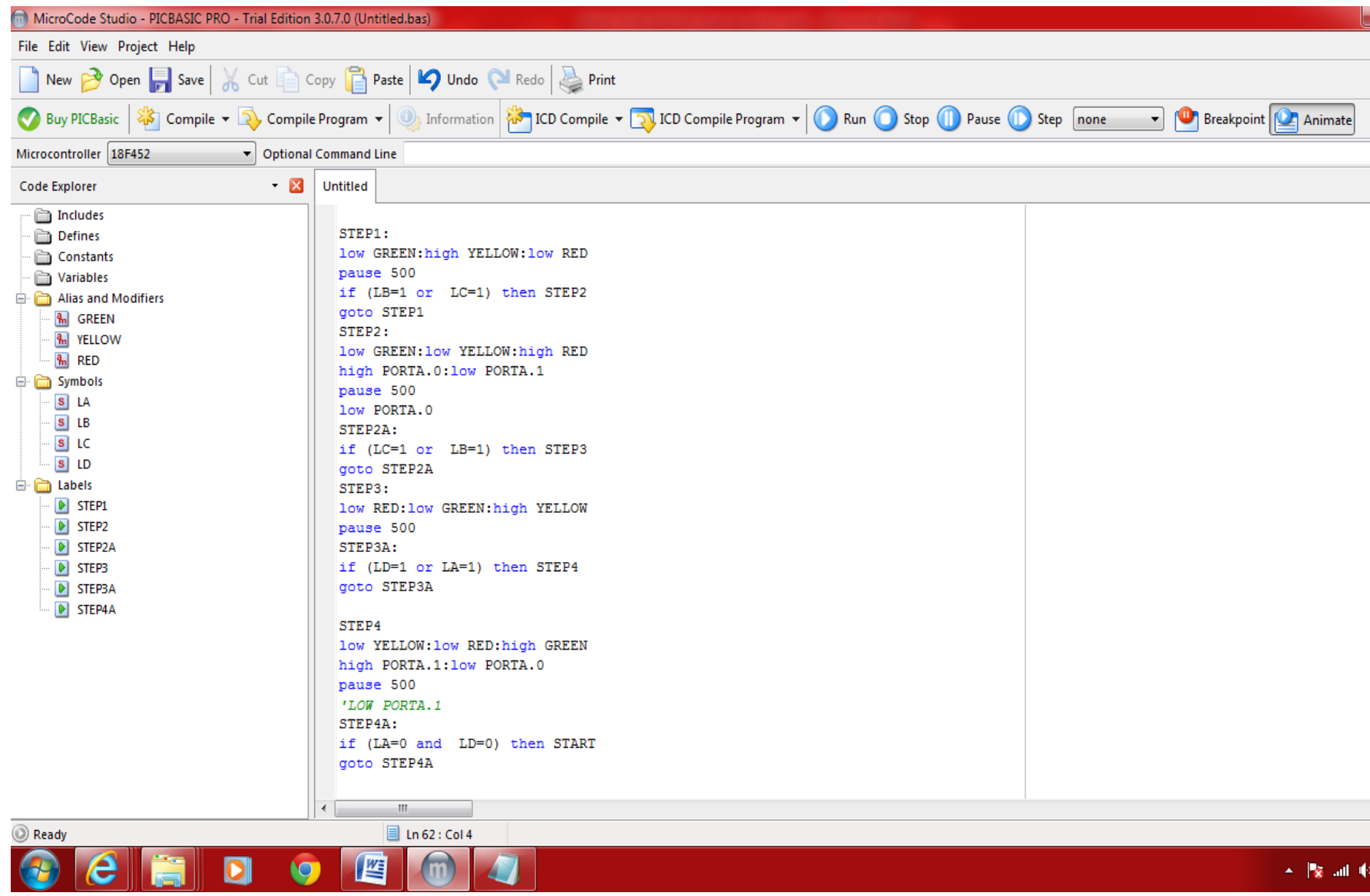

Figure 9: Screenshot showing the Level Crossing Program Development 

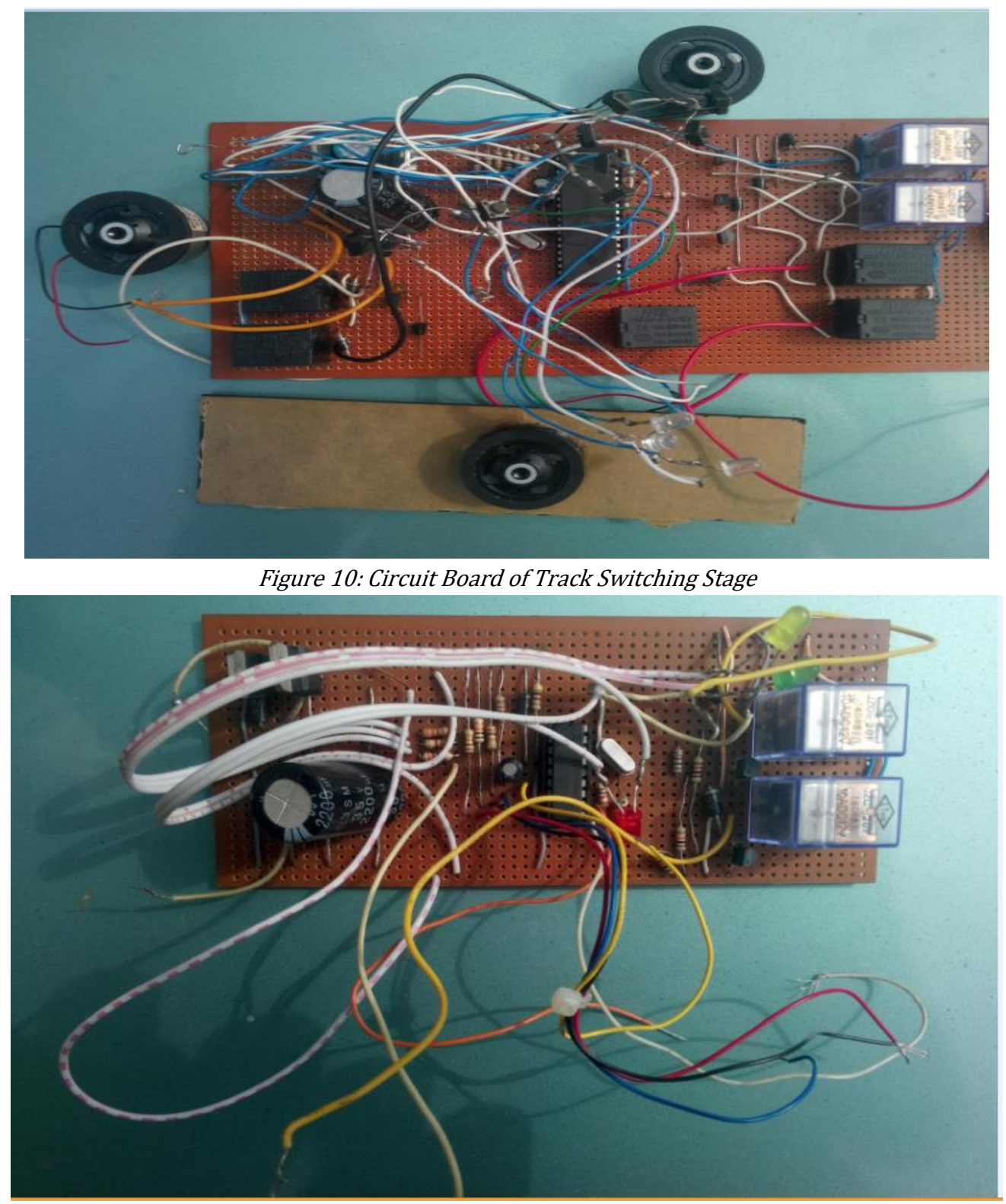

Figure 11: Circuit Board of Level Crossing Stage

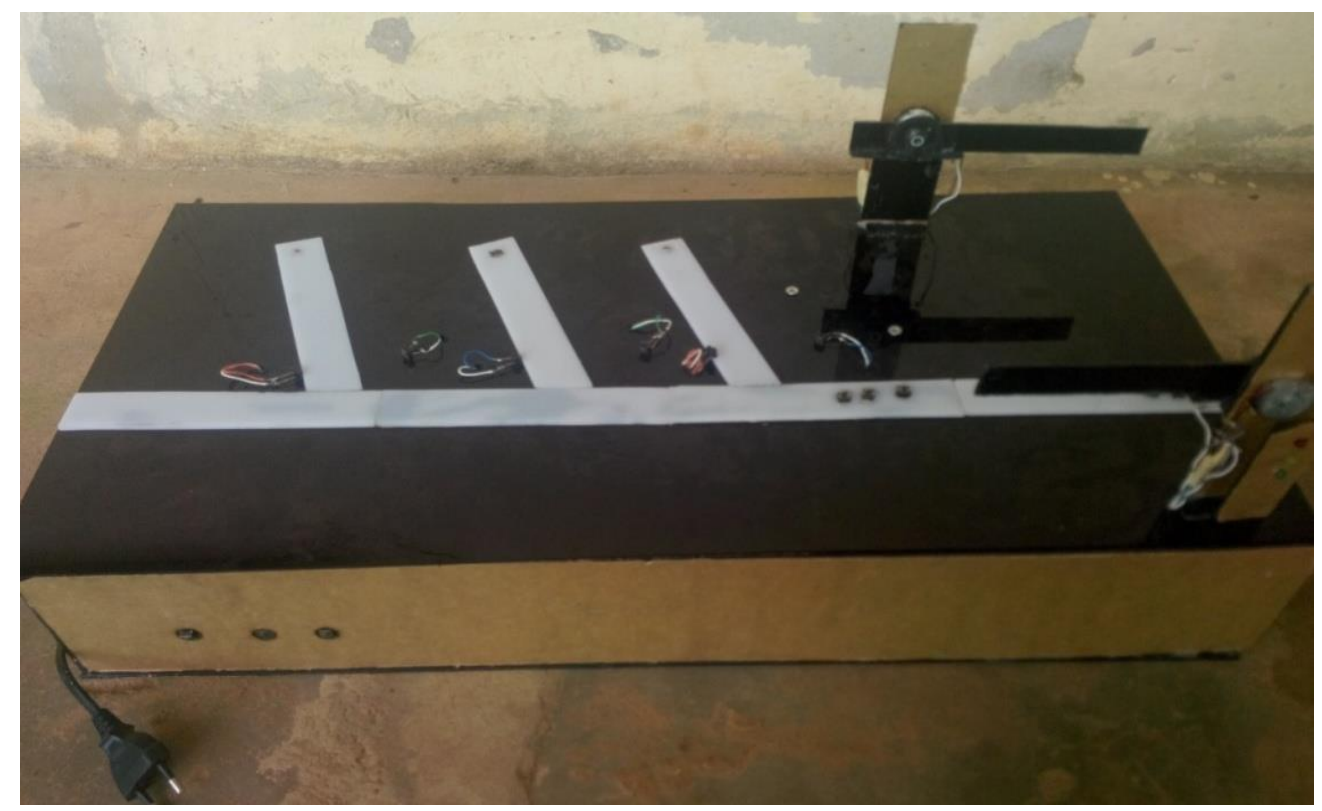

Figure 12: Picture of Prototype of the Computerized Railway Station Traffic Control System 


\section{DISCUSSION}

Two different microcontrollers have been used in this project because of the large number of Input/Output (I/O) pins required to drive all the peripheral devices connected to the microcontrollers. This also inhibits the implementation of the anticlockwise rotation of motors at the track switching stage for returning the shifted track to the original position after its operation. This project can be carried out with a single microcontroller that has the required number of I/O pins. H-bridge drivers can also be implemented with the motors at the track switching stage to control the return of any shifted track. The system described in this project has been constructed to operate a small gate at the level crossing stage and a low weight track at the track switching stage in order to demonstrate the workability of the design. The actual materials can still be used with the control system described but the driver circuitry must use components that can handle more power required for expected result to be realized.

\section{CONCLUSION}

The computerized railway station traffic control system that has been successfully designed and built in this work is meant to provide a reliable safety measure against railway accident, to help in sequential parking of trains in station yard and also to give the train priority over road vehicle at the level crossing junction. The system achieves a good measure of security with the aids of microcontrollers, electric motors and micro switches which serve as sensors. It can be modified to industrial standard using components that can handle more power required for expected result to be realized.

\section{REFERENCES}

[1] Azim, R. S., Mahmud, K., and Das, C. K., "Automatic Track Switching System with Computerized Control from the Central Monitoring Unit", International Journal of $u$ - and e- Service and Technology, 2014, 20(9),p.201-212. http://www.sersc.org/journals/IJUNESST/vol7_no1/18. pdf (accessed on 27/09/2014)

[2] Antoni, M., "Formal Validation Method and Tools for French Computerized Railway Interlocking System", IJR
International Journal of Railway, 2(3),p.99-106. http://ieexplore.ieee.org $>\ldots>$ Computer\$ Industrial Engine (accessed on 28/09/2014) 2009.

[3] Hwang, J., and Jo, H, "Hazard Identification of Railway Signaling System Using PHA and HAZOP Method", International Journal of Automation and Power Engineering (IJAPE), 2013, 2(2),p.32-39. http://www.ijape.org/Download.aspx?ID $\quad=3468$ (accessed on 27/09/2014).

[4] Banuchandar, J., Kaliraj, V., Balasubramanian, P., Deepa, S., and Thamilarasi, N., "Automated Unmanned Railway Level Crossing System", International Journal of Modern Engineering Research (IJMER), 2012, 2(1), p.458-463. http://www.ijmer.com/papers/Vol2_issue1/BX0214584 63.pdf (accessed on 30/09/2014)

[5] Krishna., Yadav, S., and Nidhi., "Automatic Railway Gate Control Using Microcontroller", Oriental Journal of Computer Science \& Technology, 6(4),p.435-440. http://computerscijournal.org/dnload/.Yadav.../ojSCSV0 6104P435-440.pdf (accessed on 30/09/2014). 2013,

[6] Signalling Solutions Limited, Borehamwood Industrial Park, Rowley Lane, Borehamwood, Hertfordshire, WD6 5PZ, www.signallingsolutions.com

[7] Bedrich, S., and Gu, X.,“GNSS-Based Sensor Fusion for Safety-Critical Applications in Rail Traffic", http://www.galileo-services.org/library/2.1-Bedrich.pdf (accessed on 03/04/2015)

[8] Salmi, P., and Torkkeli, M., "Inventions Utilizing Satellite Navigation Systems in the Railway Industry- An Analysis of Patenting Activity", Journal of Technology Management and Innovation, Vol. 4, Issue 3, pp. 46-58. 2009,.

[9] Dipoppa, G., D’Alessandro, G., Semprini, R., and Tronci, E, "Integrating Automatic Verification of Safety Requirements in Railway Interlocking System Design", The 6th IEEE International Symposium on High Assurance Systems Engineering (HASE'01), Washington, USA, October 22-24. 2001.

[10] MicroEngineering Labs Incorporation. (online),microcode studio IDE/Debugger/Simulator. Available at:www.pbp3.com/downloads/PBP_Reference manual.pdfb (Accessed on 06/10/2014) 2014.

[11] Labcenter Electronics. (online2014), Proteus Design Suite. Available at: www.labcenter.com/index.cfm (accessed on 06/10/2014).

[12] Universal Programmer. (online2014),Universal Programmer Model: TOP 2005. Available at: http://www.nskelectronics.com/files/top_2007_spec.pdf (accessed on 04/10/2014). 